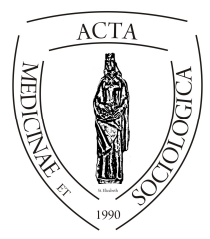

Acta Medicinae et

Sociologica (2020)

UNIVERSITY OF

DEBRECEN

Vol. 11. No. 30. (141-142)

FACULTY OF

HEALTH

doi:

NYÍREGYHÁZA

\title{
Review of \\ Diversity and Complexity, written by Camilla Pagani, Nova Science, 2019.
}

Marzanna Farnicka

Professor (Adjunct). University of Zielona Góra, Institiute of Psychology. Zielona Gora, Aleja Wojska Polskiego 69.

INFO

Marzanna Farncika

m.farnicka@wpps.uz.zgora.pl

The main aim of the book Diversity and Complexity is to understand socio - cultural diversity as one of the numerous interconnected constituents of a larger system that is formed by the numberless kinds of diversities (in terms of age, gender, status, education, species, "inner" diversity, etc.).

Who is the author? Camilla Pagani is a researcher at the Institute of Cognitive Sciences and Technologies (ISTC) of the Italian National Research Council (CNR). She has a degree in Modern Languages and Literature, a PhD in Anglo-American Literature, and a degree in Psychology. As the Head of the Project "The sense of diversity and its psychological implications", she has mostly been involved in the following research areas: youth's attitudes toward multiculturalism. She is also Head of the "Migrations and Education" Unit of the "Migration Project" of the "Dipartimento di Scienze Umane e Sociali, Patrimonio Culturale" of the National Research Council. Therefore, she is a Fellow of the University of Denver and "Expert Evaluator" of European projects for the European Commission, a member of IAIE (International Association for Intercultural Education) and of ISAZ (International Society of Anthrozoology).

What is the book about? The book consists of 11 chapters: four theoretical (1 4), one research (5) and six with a lot of material for discussion and reflection (6 11). In the theoretical part the author discusses the definition of diversity and its justification, and the definition of complexity. It also presents the advantages of integrating the socio-psychological perspective and complexity theory. 
In the chapter entitled "Complexity and its Relationship with Diversity: An Analysis of Data from our Research on Children's and Adolescents' Attitudes to Multiculturalism" the author focuses on children's and adolescents' attitudes towards multiculturalism in the Italian context. Camilla Pagani refers to her studies in this field, which were conducted for almost twenty years.

In the subsequent chapters the author discusses the manifestations of the relationship with diversity within a complexity perspective and in connection with such issues as complex thinking, racism, empathy, and human-animal relations. Two chapters are dedicated to the analysis of this relationship in literature and in cinema and photography respectively.

The author provides a broad definition of diversity. According to Camilla Pagani, this definition is one of the cornerstones of the publication. This is in line with the holographic principle (the part in the whole and the whole in the part), which, according to Morin (2008), is one of the three principles (the other two being the dialogic and the recursive) that helps understand complexity.

In the book, the development and the use of a complexity perspective in all human situations are analysed with a special focus on the use of non-linear processes and on the possibility of identifying the emergent idea or principle that can possibly provide the solution or one of the possible solutions in effectively addressing and possibly resolving a specific issue.

Another important component in the analysis of the relationship with diversity within a complexity perspective is the role of the Subject in the act of observation. This means that within this perspective the Subject and the object are and have to be constitutive of each other, and the processes of observation and self-observation should be integrated. This approach, whose significance has been widely accepted as far as the aesthetic experience is concerned, is constitutive of all the acts of knowing.

In summary, one of the main conclusions is that some deep, primeval, probably unconscious emotions are imperiously and profoundly operating in the recent wave of racism and opposition to new and old immigrants in many countries. 